\title{
Sistem Pendukung Keputusan Menentukan Duta Sekolah untuk Lomba Kompetensi Siswa Menggunakan Metode Elimination Et Choix Traduisant la Realite (Electre)
}

\author{
Beni Andika, Hendryan Winata, Rico Imanta Ginting \\ STMIK Triguna Dharma
}

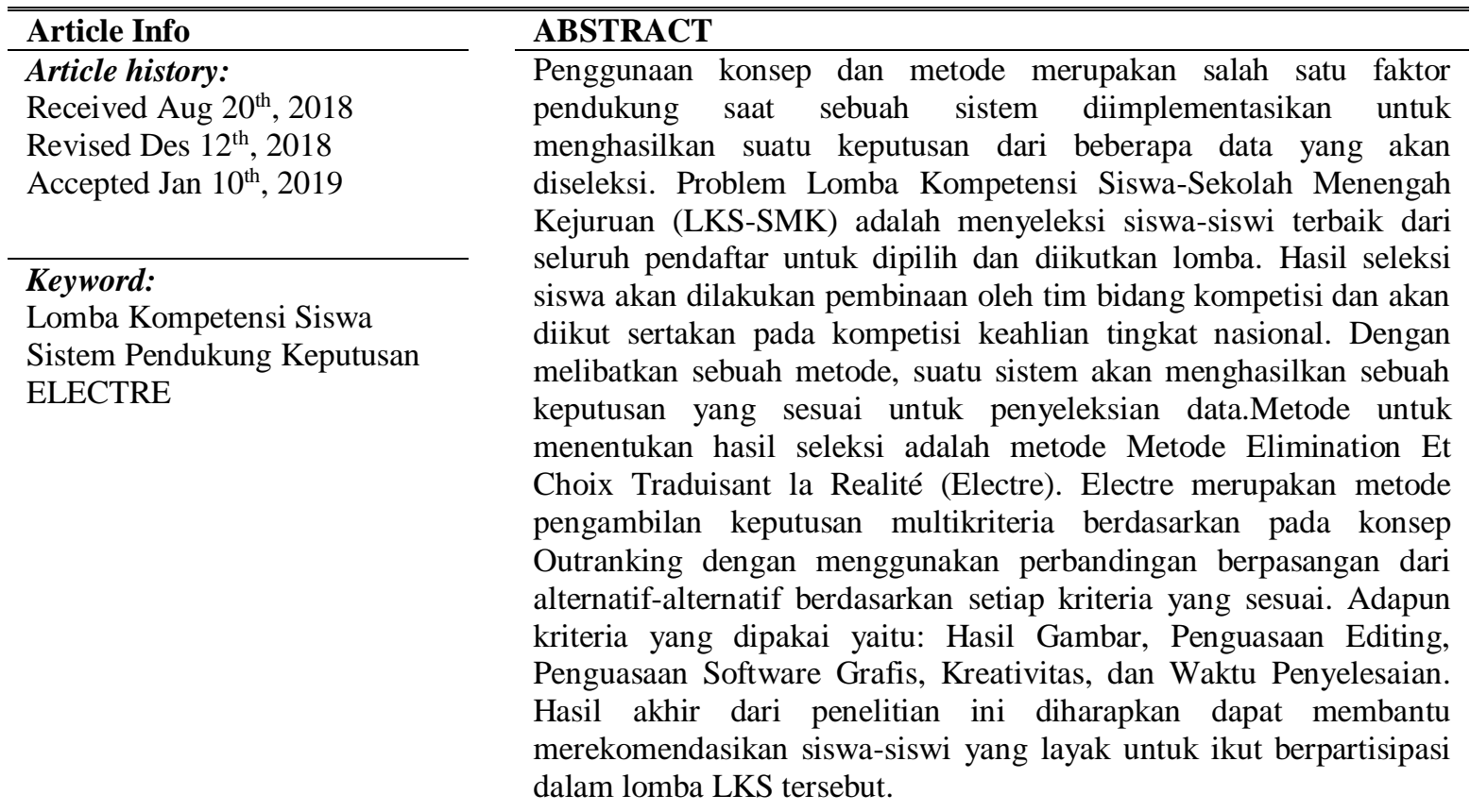

Copyright @ 2019 STMIK Triguna Dharma. All rights reserved.

\section{PENDAHULUAN}

Lomba Kompetensi Siswa adalah kompetisi tahunan antar siswa pada jenjang SMK sesuai bidang keahlian yang diajarkan pada SMK peserta LKS ini setara dengan OSN (Olimpiade Sains Nasional) yang diadakan di tingkat SMP/SMA. Pemenang LKS tingkat Nasional akan mewakili Indonesia ke ASEAN Skills (Kompetisi Keahlian tingkat ASEAN) dan World Skills International Competition (Kompetisi Keahlian tingkat Dunia).

Sistem Pendukung Keputusan (SPK) adalah bagian dari sistem informasi komputer yang berbasis pengetahuan akan manajemen pengetahuan yang dipakai untuk mendukung keputusan. Pemilihan siswa di Yayasan Pendidikan Islam Asy-Syafi'iyah Internasional Medan dilakukan berdasarkan pengamatan dan melihat prestasi siswa namun tidak ada sistem yang mendukung bahwa calon yang dipilih memang layak dicalonkan, maka diperlukanlah sebuah sistem untuk mendukung dan memperkuat bahwa pemilihan siswa bisa dibuktikan oleh aplikasi ini. Metode Elimination Et Choix Traduisant la Realite (Electre) merupakan salah satu metode pengambilan keputusan multikriteria berdasarkan pada konsep outranking dengan menggunakan perbandingan berpasangan dari alternatif-alternatif berdasarkan setiap kriteria yang sesuai.

Sistem Pendukung Keputusan memungkinkan sebuah keputusan dapat dihasilkan secara akurat dan cepat, dalam hal ini memberikan keputusan penentuan siswa untuk berpartisipasi dalam LKS Tingkat kota Medan.

\section{LANDASAN TEORI}

\subsection{Sistem Pendukung Keputusan}

Sistem Pendukung Keputusan merupakan sistem informasi interaktif yang menyediakan informasi, pemodelan dan pemanipulasi data. Sistem ini digunakan untuk pengambilan keputusan dalam situasi yang semiterstruktur dan tidak terstruktur (Kusrini 2007:15) 
Sistem Pendukung Keputusan adalah sekumpulan prosedur berbasis model untuk data pemrosesan dan penilaian guna membantu para manajer mengambil keputusan. (Turban, 2005 : 137)

Ada beberapa karakteristik dari sistem pendukung keputusan adalah sebagai berikut:

1. Sistem pendukung keputusan memberikan dukungan bagi pengambil keputusan pada situasi semi terstruktur dan tak terstruktur dengan memadukan pertimbangan manusia dan informasi terkomputerisasi.

2. Sistem pendukung keputusan memberikan dukungan bagi pengambil keputusan pada situasi semi terstruktur dan tak terstruktur dengan memadukan pertimbangan manusia dan informasi terkomputerisasi.

3. Dukungan di semua fase proses pengambilan keputusan, yaitu intelligence, design, choice dan implementation.

4. Peningkatan efektivitas dari pengambilan keputusan daripada efisiensi.

5. Pengguna akhir bisa mengembangkan dan memodifikasi sendiri sistem sederhana.

6. Dapat digunakan sebagai standalone oleh seorang pengambil keputusan pada satu lokasi atau didistribusikan di suatu organisasi secara keseluruhan dan di beberapa organisasi sepanjang rantai persediaan.

\subsection{Metode Elimination Et Choix Traduisant la Realite (Electre)}

electre merupakan salah satu metode pengambilan keputusan multikriteria berdasarkan pada konsep outranking dengan menggunakan perbandingan berpasangan dari alternatif-alternatif berdasarkan setiap kriteria yang sesuai.

Metode electre digunakan pada kondisi dimana alternatif yang kurang sesuai dengan kriteria dieliminasi, dan alternatif yang sesuai dapat dihasilkan. Dengan kata lain, electre digunakan untuk kasus-kasus dengan banyak alternatif namun hanya sedikit kriteria yang dilibatkan.

Suatu alternatif dikatakan mendominasi alternatif yang lainnya jika satu atau lebih kriterianya melebihi (dibandingkan dengan kriteria dari alternatif yang lain) dan sama dengan kriteria lain yang tersisa (Kusumadewi dkk, 2006).

Electre dimulai dari membentuk perbandingan berpasangan setiap alternatif di setiap kriteria (xij) (Fuzzy Multi-Attribute Decision Making (Fuzzy MADM), 2006). Nilai ini harus dinormaliasikan ke dalam suatu skala yang dapat diperbandingkan (rij)

Rumus Membentuk perbandingan berpasangan setiap alternatif pada setiap kriteria dan dinormalisasi ke dalam suatu skala yang dapatdibandingkan:

$$
r_{i j=\frac{x_{i j}}{\sum_{i=1}^{M} x_{i j}^{2}} ; \text { untuki }=1,2,3, \ldots, m j=1,2,3, \ldots, n}
$$

Keterangan:

$\mathrm{r}_{\mathrm{ij}}=$ Nilai normalisasi kriteria

$\mathrm{x}_{\mathrm{ij}}=$ Nilai matriks hasil perbandingan

Rumus untuk menentukan bobot pada setiap kriteria yang mengekspresikan kepentingan relatifnya (Wi) adalah sebagai berikut:

$$
w=w_{1}, w_{2}, \ldots . w_{n} ; \text { dengan } \sum_{j}^{\not n} 1^{m} w_{j}=1
$$

Keterangan:

$\mathrm{W}_{\mathrm{ij}}=$ Nilai bobot kriteria

\subsection{Lomba Kompetensi Siswa}

Lomba Kompetensi Siswa adalah kompetisi tahunan antar siswa pada jenjang SMK sesuai bidang keahlian yang diajarkan pada SMK peserta. LKS ini setara dengan OSN (Olimpiade Sains Nasional) yang diadakan di SMP/SMA. Pemenang LKS tingkat Nasional akan mewakili Indonesia ke ASEAN Skills (Kompetisi Keahlian tingkat ASEAN) dan World Skills International Competition (Kompetisi Keahlian tingkat Dunia). Siswa yang mengikuti LKS adalah siswa yang telah lolos seleksi tingkat kabupaten dan provinsi dan karenanya adalah siswa-siswa terbaik dari provinsinya masing-masing. Lomba kompetensi siswa diadakan setiap tahunnya. Kegiatan ini merupakan salah satu bagian dari rangkaian seleksi untuk mendapatkan siswasiswi terbaik dari seluruh Indonesia yang akan dibimbing lebih lanjut oleh tim bidang kompetisi masing dan akan diikutsertakan di kompetisi keahlian tingkat nasional (Juknis LKS, 2011). 


\section{PEMBAHASAN DAN HASIL}

Dalam menyelesaikan permasalahan yang terjadi pada YPI Asy-Syafi'iyah Internasional Medan, dibutuhkan sebuah sistem yang mampu mempermudah Pihak YPI Asy-Syafi'iyah Internasional Medan dalam menentukan nilai objek pajak bumi dan bangunan yang nantinya dapat diaplikasikan dalam sebuah sistem komputer dengan menggunakan metode Elimination Et Choix Traduisant la Realite. Setiap output yang dihasilkan oleh sistem harus sesuai dengan hasil yang diharapkan. Berikut adalah kriteria-kriteria dalam melakukan penilaian siswa yang layak berpartisipasi dalam lomba LKS bidang desain grafis.

Tabel.1 Kriteria Menentukan Nilai Objek Pajak Bumi dan Bangunan

\begin{tabular}{|c|c|c|}
\hline No & Kode & Keterangan \\
\hline 1 & C1 & Hasil Gambar \\
\hline 2 & C2 & Penguasaan Editing \\
\hline 3 & C3 & Krenguasaan Software Grafis \\
\hline 4 & C4 & Waktu Penyelesaian \\
\hline 5 & C5 & . \\
\hline
\end{tabular}

Tabel.2 Alternatif

\begin{tabular}{|c|c|l|}
\hline No. & Nama Alternatif & \multicolumn{1}{c|}{ Keterangan } \\
\hline 1 & A01 & Andi Sanjaya \\
\hline 2 & A02 & Barik Angkasa \\
\hline 3 & A03 & Fahreza Afif Htb. \\
\hline 4 & A04 & Muhammad Ikhsan Fajar \\
\hline 5 & A05 & Siti Rahma Sembiring \\
\hline
\end{tabular}

Tabel.3 Bobot Penilaian

\begin{tabular}{|c|c|c|}
\hline No. & Skala Penilaian & Nilai \\
\hline 1 & $81-100$ & 5 \\
\hline 2 & $61-80$ & 4 \\
\hline 3 & $41-60$ & 3 \\
\hline 4 & $21-40$ & 2 \\
\hline 5 & $1-20$ & 1 \\
\hline
\end{tabular}

Tabel.4 Bobot Preferensi

\begin{tabular}{|c|c|c|}
\hline No. & Nilai & Keterangan \\
\hline 1 & 5 & Sangat Baik \\
\hline 2 & 4 & Baik \\
\hline 3 & 3 & Cukup \\
\hline 4 & 2 & Kurang Baik \\
\hline 5 & 1 & Buruk \\
\hline
\end{tabular}

Tabel.5 Rekapitulasi Data Calon Duta Sekolah Untuk Berpartisipasi Dalam Lomba Kompetensi Siswa Bidang Desain Grafis Tingkat Se-Kota Medan

\begin{tabular}{|c|l|c|c|c|c|c|}
\hline \multirow{2}{*}{ No. } & \multirow{2}{*}{ Alternatif } & \multicolumn{5}{|c|}{ Kriteria } \\
\cline { 2 - 6 } & $\begin{array}{c}\text { Hasil } \\
\text { Gambar }\end{array}$ & $\begin{array}{c}\text { Penguasaan } \\
\text { Editing }\end{array}$ & $\begin{array}{c}\text { Penguasaan Software } \\
\text { Grafis }\end{array}$ & Kreativitas & $\begin{array}{c}\text { Waktu } \\
\text { Penyelesaian }\end{array}$ \\
\hline 1 & Andi Sanjaya & 78 & 60 & 75 & 83 & 50 \\
\hline 2 & Barik Angkasa & 60 & 72 & 75 & 80 & 30 \\
\hline 3 & Fahreza Afif Htb. & 83 & 80 & 79 & 79 & 80 \\
\hline 4 & Mhd Ikhsan Fajar & 75 & 81 & 58 & 75 & 70 \\
\hline 5 & $\begin{array}{l}\text { Siti Rahma } \\
\text { Sembiring }\end{array}$ & 80 & 79 & 79 & 81 & 60 \\
\hline
\end{tabular}


Tabel.6 Kecocokan Alternatif Terhadap Setiap Kriteria

\begin{tabular}{|c|c|c|c|c|c|c|}
\hline \multirow{2}{*}{ No. Alternatif } & \multicolumn{5}{|c|}{ Kriteria } \\
\cline { 3 - 7 } & & $\mathbf{C 1}$ & $\mathbf{C 2}$ & $\mathbf{C 3}$ & $\mathbf{C 4}$ & C5 \\
\hline 1 & A01 & 4 & 3 & 4 & 5 & 3 \\
\hline 2 & A02 & 3 & 3 & 3 & 4 & 2 \\
\hline 3 & A03 & 5 & 4 & 5 & 4 & 4 \\
\hline 4 & A04 & 4 & 5 & 3 & 4 & 4 \\
\hline 5 & A05 & 4 & 4 & 4 & 5 & 3 \\
\hline
\end{tabular}

Diketahui :

1. $\mathrm{Ai}=01$ (A01), 02 (A02), 03 (A03), 04 (A04), 05 (A05).

2. $\mathrm{Cj}=$ Hasil Gambar (C1), Penguasaan Editing (C2), Penguasaan Software Grafis (C3), Kreativitas (C4), dan Waktu Penyelesaian (C5).

3. Rangking kecocokan setiap alternatif pada setiap kriteria (terdapat pada Tabel.4).

Bobot preferensi untuk setiap kriteria $(\mathrm{C} 1, \mathrm{C} 2, \mathrm{C} 3, \mathrm{C} 4, \mathrm{C} 5)=(5,4,3,4,4)$.

Keterangan :

1. Nilai bobot preferensi untuk Hasil Gambar (C1) bernilai 5.

2. Nilai bobot preferensi untuk Penguasaan Editing (C2) bernilai 4.

3. Nilai bobot preferensi untuk Penguasaan Software Grafis (C3) bernilai 3.

4. Nilai bobot preferensi untuk Kreativitas (C4) bernilai 4.

5. Nilai bobot preferensi untuk Waktu Penyelesaian (C5) bernilai 4.

Penyelesaian :

3.2.7 Membuat Matriks Keputusan Ternormalisasi R

$$
r i j=\frac{x i j}{\sqrt{\sum_{i=j}^{m} x i j^{2}}}
$$

\section{Menghitung Matriks V}

$\mathrm{V}=\mathrm{Wj}$.Rij (menghitung bobot ternormalisasi)

$\mathrm{W}=$ bobot preferensi $(5,4,3,4,4)$.

$$
\mathrm{V}=\left[\begin{array}{llllll}
5 \times 0,4417 & 4 \times 0,3464 & 3 \times 0,4619 & 4 \times 0,5051 & 4 \times 0,4082 \\
5 \times 0,3313 & 4 \times 0,3464 & 3 \times 0,3464 & 4 \times 0,4041 & 4 \times 0,2722 \\
5 \times 0,5522 & 4 \times 0,4619 & 3 \times 0,5774 & 4 \times 0,4041 & 4 \times 0,5443 \\
5 \times 0,4417 & 4 \times 0,5774 & 3 \times 0,3464 & 4 \times 0,4041 & 4 \times 0,5443 \\
5 \times 0,4417 & 4 \times 0,4619 & 3 \times 0,4619 & 4 \times 0,5051 & 4 \times 0,4082
\end{array}\right]
$$

Maka akan menghasilkan matriks V seperti dibawah ini :

Menentukan Himpunan Concordance dan Disordance

$$
\mathrm{V}=\left[\begin{array}{lllll}
2,2086 & 1,3856 & 1,3856 & 2,0203 & 1,6330 \\
1,6565 & 1,3856 & 1,0392 & 1,6162 & 1,0887 \\
2,7608 & 1,8475 & 1,7321 & 1,6162 & 2,1773 \\
2,2086 & 2,3094 & 1,0392 & 1,6162 & 2,1773 \\
2,2086 & 1,8475 & 1,3856 & 2,0203 & 1,6330
\end{array}\right]
$$


1. Concordance

$C k l=\{j, v k j \geq v l j\}, u n t u k j=1,2,3, \ldots n$

Matriks concordancedicari dengan membandingkan tiap-tiap (baris) alternatif pada kriteria-kriteria yang ada dibawah ini :

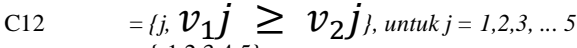

$$
\begin{aligned}
& =\{1,2,3,4,5\} \\
& \mathrm{C} 13=\left\{j, v_{1} j \geq \boldsymbol{v}_{3} j\right\} \text {,untuk } j=1,2,3, \ldots 5 \\
& =\{4\} \\
& \mathrm{C} 14=\left\{j, v_{1} j \geq \boldsymbol{v}_{4} j\right\}, \text { untukj }=1,2,3, \ldots 5 \\
& =\{1,3,4\} \\
& \mathrm{C} 15=\left\{j, \boldsymbol{v}_{1} j \geq \boldsymbol{v}_{5} j\right\}, \text { untuk } j=1,2,3, \ldots 5 \\
& =\{1,3,4,5\} \\
& \mathrm{C} 21 \quad=\left\{j, \boldsymbol{v}_{2} j \geq \boldsymbol{v}_{1} j\right\}, \text { untuk } j=1,2,3, \ldots 5 \\
& =\{2\} \\
& \mathrm{C} 23 \quad=\left\{j, v_{2} j \geq \boldsymbol{v}_{3} j\right\}, \text { untuk } j=1,2,3, \ldots 5 \\
& =\{4\} \\
& \mathrm{C} 24 \\
& =\left\{j, \mathcal{V}_{2} j \geq \boldsymbol{V}_{4} j\right\}, \text { untuk } j=1,2,3, \ldots 5 \\
& =\{3,4\} \\
& \text { C25 } \\
& =\left\{j, v_{2} j \geq \boldsymbol{v}_{5} j\right\}, \text { untuk } j=1,2,3, \ldots 5 \\
& =\{\} \\
& \mathrm{c} 31=\left\{j, v_{3} j \geq v_{1} j\right\} \text { untuk } j=1,2,3, \ldots 5 \\
& =\{1,2,3,5\} \\
& \text { C32 } \\
& =\left\{j, v_{3} j \geq v_{2} j\right\}, \text { untuk } j=1,2,3, \ldots 5 \\
& =\{1,2,3,4,5\} \\
& \text { C34 } \\
& =\left\{j, v_{3} j \geq v_{4} j\right\}, \text { untuk } j=1,2,3, \ldots 5 \\
& =\{1,3,4,5\} \\
& \mathrm{C} 35 \quad=\left\{j, v_{3} j \geq v_{5} j\right\}, \text { untukj }=1,2,3, \ldots 5 \\
& =\{1,2,3,5\} \\
& =\left\{j, v_{4} j \geq v_{1} j\right\}, \text { untukj=1,2,3,..5 } \\
& =\{1,2,5\} \\
& \text { C42 } \\
& \begin{array}{l}
=\left\{j, v_{4} j \geq v_{2} j\right\}, \text { untukj }=1,2,3, \ldots 5 \\
=\{1,2,3,4,5\}
\end{array}
\end{aligned}
$$

2. Disordance

Sebuah kriteria dalam suatu alternatif termasuk disordance jika :

$$
D k l=\{j, v k j \leq v l j\}, \text { untuk } j=1,2,3, \ldots n
$$

D12

$$
=\left\{j, v_{1} j \leq v_{2} j\right\}, \text { untuk } j=1,2,3, \ldots 5
$$

$$
=\{\}
$$

$=\left\{j, v_{1} j \leq v_{3} j\right\}$, untuk $j=1,2,3, \ldots 5$

$$
=\{1,2,3,5\}
$$

D14

$=\left\{j, v_{1} j \leq v_{4} j\right\}$, untuk $j=1,2,3, \ldots 5$

$=\{2,5\}$

D15

$=\left\{j, v_{1} j \leq v_{5} j\right\}$, untuk $j=1,2,3, \ldots 5$

$=\{2\}$

D21

$=\left\{j, v_{2} j \leq v_{1} j\right\}$, untuk $j=1,2,3, \ldots 5$

$=\{1,3,4,5\}$

D23

$=\left\{j, v_{2} j \leq v_{3} j\right\}$, untuk $j=1,2,3, \ldots 5$

$=\{1,2,3,5\}$

D24

$=\left\{j, v_{2} j \leq v_{4} j\right\}$, untuk $j=1,2,3, \ldots 5$

$=\{1,2,5\}$

$=\left\{j, \boldsymbol{v}_{2} j \leq \boldsymbol{V}_{5} \boldsymbol{j}\right\}$, untuk $j=1,2,3, \ldots 5$

$=\{1,2,3,4,5\}$

D31

$=\left\{j, v_{3} j \leq v_{1} j\right\}$, untuk $j=1,2,3, \ldots 5$

$=\{4\}$

$=\left\{j, v_{3} j \leq v_{2} j\right\}$, untuk $j=1,2,3, \ldots 5$

Menentukan Matriks Dominan Concordance dan Disordance

1. Menghitung matriks dominan concordance

Nilai threshold $(\underline{c})$ adalah :

$$
\begin{aligned}
\underline{C} & =\frac{\sum_{k=1}^{m} \sum_{l=1}^{m} c k l}{m(m-1)} \\
& =\frac{20+4+12+16+4+4+7+0+16+20+16+16+13+20+12+13+20+20+8+12}{5(5-1)} \\
& =\frac{253}{20}=12,65
\end{aligned}
$$

Elemen matriks $\mathrm{F}$ ditentukan sebagai berikut :

$F_{k l}=1$,jika $C_{k l} \geq \underline{c}$

$F_{k l}=0$, jika $C_{k l} \leq \underline{c}$

Sehingga, matriks dominan corcondance adalah :

2. Menghitung matriks dominan disordance

$$
\mathrm{F}=\left[\begin{array}{ccccc}
- & 1 & 0 & 0 & 1 \\
0 & - & 0 & 0 & 0 \\
1 & 1 & - & 1 & 1 \\
1 & 1 & 0 & - & 1 \\
1 & 1 & 0 & 0 & -
\end{array}\right]
$$

Nilai threshold $(d)$ adalah :

$$
\begin{aligned}
\underline{D} & =\frac{\sum_{k=1}^{m} \sum_{l=1}^{m} d k l}{m(m-1)} \\
& =\frac{1+0,7318+0,437+0+0+0+0+0+1+1+1+1+1+1+0,667+1+1+1+0,732+0,7423+1+0+0}{5(5-1)} \\
& =\frac{13,3100}{20}=0,665
\end{aligned}
$$

Elemen matriks $\mathrm{G}$ ditentukan sebagai berikut :

$G_{k l}=1$, jika $D_{k l} \geq \underline{d}$

$$
G_{k l}=0, j i k a D_{k l} \leq \underline{d}
$$


Sehingga, matriks dominan disordance adalah :

$$
\mathrm{G}=\left[\begin{array}{ccccc}
- & 1 & 1 & 0 & 0 \\
0 & - & 0 & 0 & 0 \\
1 & 1 & - & 1 & 1 \\
1 & 1 & 1 & - & 1 \\
1 & 1 & 1 & 1 & -
\end{array}\right]
$$

Menentukan Aggregate Dominance Matriks

Rumus umum untuk aggregate dominan matriks adalah :

$$
\begin{aligned}
& e 12=0 \times 0=0 \\
& e 13=1 \times 1=1 \\
& e 14=1 \times 1=1 \\
& e 15=1 \times 1=1 \\
& e 21=1 \times 1=1 \\
& e 23=1 \times 1=1 \\
& e 24=1 \times 1=1 \\
& e 25=1 \times 1=1 \\
& e 31=0 \times 1=0 \\
& e 32=0 \times 0=0 \\
& e 34=0 \times 1=0 \\
& e 35=0 \times 1=0 \\
& e 41=0 \times 1=0 \\
& e 42=0 \times 1=0 \\
& e 43=1 \times 1=1 \\
& e 45=0 \times 1=0 \\
& e 51=1 \times 0=0 \\
& e 52=0 \times 0=0 \\
& e 53=1 \times 1=1 \\
& e 54=1 \times 1=1
\end{aligned}
$$

$$
E k l=f k l \times g k l
$$

Sehingga, aggregate matriks dominan adalah :

$$
E=\left[\begin{array}{ccccc}
- & 1 & 0 & 0 & 0 \\
0 & - & 0 & 0 & 0 \\
1 & 1 & - & 1 & 1 \\
1 & 1 & 0 & - & 1 \\
1 & 1 & 0 & 0 & -
\end{array}\right]
$$

Kemudian hitung total nilai dari tiap-tiap alternatif seperti sebagai berikut :

$$
\mathrm{A} 01=1
$$

$\mathrm{A} 02=0$

$\mathrm{A} 03=4$

$\mathrm{A} 04=3$

$\mathrm{A} 05=2$

Perangkingan dilakukan untuk menentukan jumah atau nilai nilai objek pajak bumi dan bangunan pada Dinas Pendapatan Daerah.

Maka dari total perhitungan diatas dapat disimpulkan bahwa alternatif A03 lebih baik dari alternatif A01, A02, A04, dan A05. Maka yang dipilih adalah alternatif A03 yaitu Fahreza Afif Htb menjadi duta sekolah untuk berpartisipasi dalam lomba kompetensi siswa bidang desain grafis tingkat se-kota Medan pada Yayasan Pendidikan Islam Asy-Syafi'iyah Internasional Medan.

Berikut ini merupakan tampilan dari form Menu Utama. Pada tampilan form menu utama terdapat beberapa menu lain nya

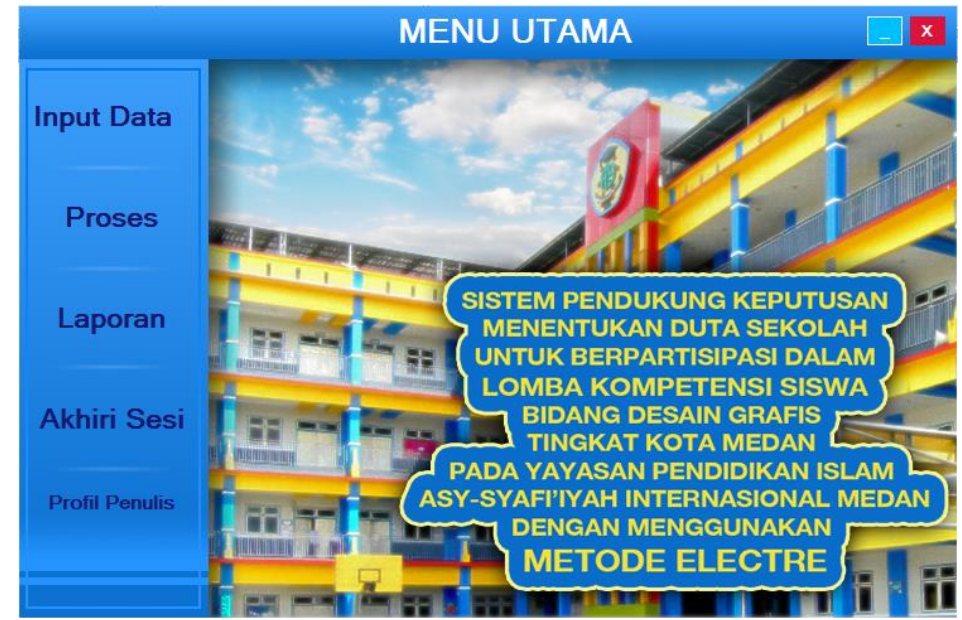

Gambar 1. Form Menu Utama 


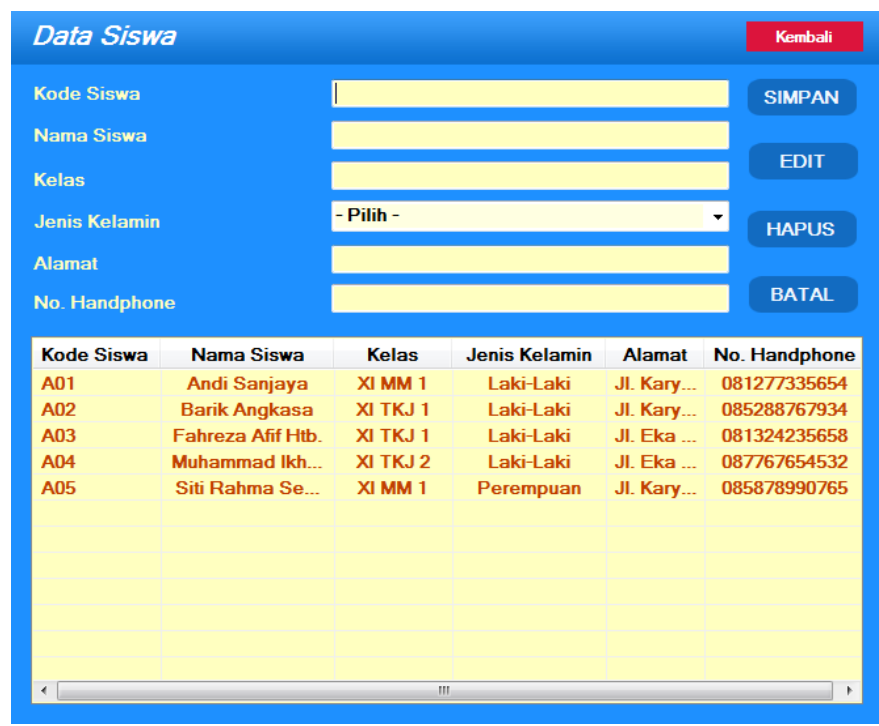

Gambar 2. Tampilan Form Data Siswa

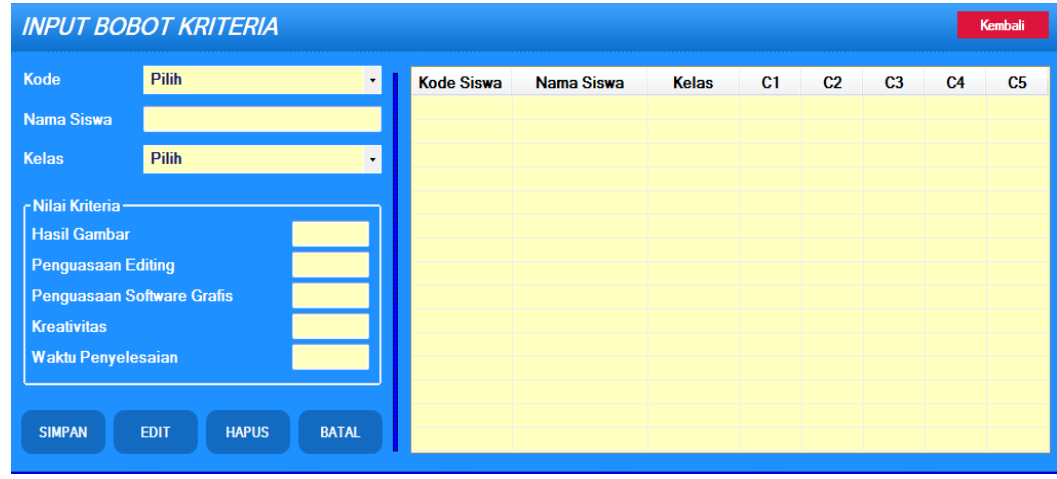

Gambar 3. Tampilan Form Penilaian

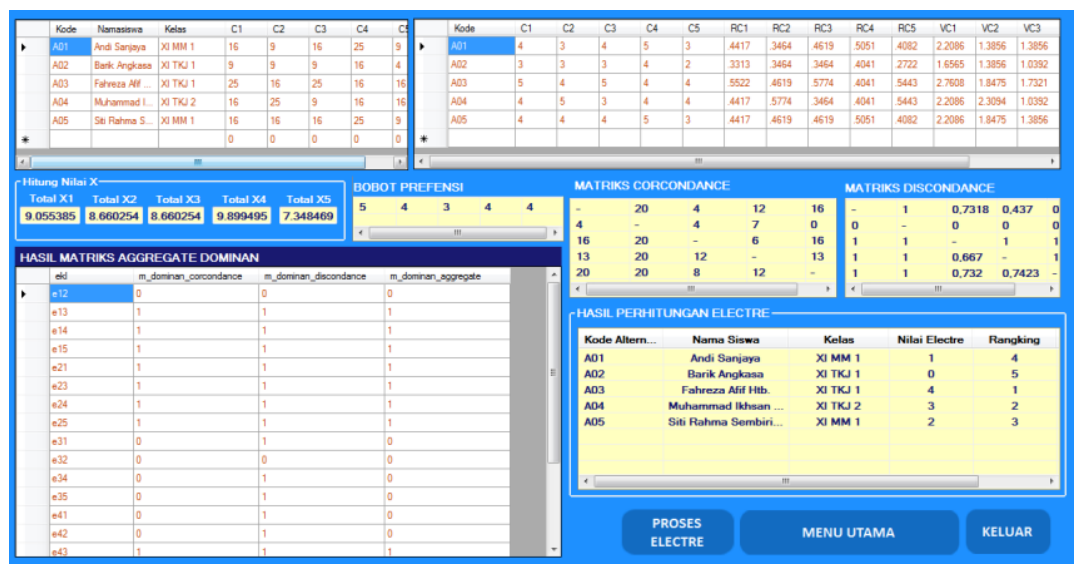

Gambar 4. Tampilan Form Analisa

\section{KESIMPULAN}

1. Sistem pengambilan keputusan pemilihan Siswa untuk Berpartisipasi dalam Lomba Kompetensi Siswa Bidang Desain Grafis pada Yayasan Perguruan Asy-Syafi'iyah Internasional Medan menggunakan Metode Elimination Et Choix Traduisant la Realite (ELECTRE) telah dibangun dengan bahasa pemrograman Visual Studio 2010.

2. Sistem pengambilan keputusan pemilihan Siswa untuk Berpartisipasi dalam Lomba Kompetensi Siswa Bidang Desain Grafis pada Yayasan Perguruan Asy-Syafi'iyah Internasional Medan menggunakan Metode Elimination Et Choix Traduisant la Realite (ELECTRE) berhasil memberikan 
rekomendasi siswa peserta LKS kepada pihak YPI. Asy-Syafi'iyah Internasional Medan berdasarkan nilai dari masing-masing kriteria dan nilai bobot.

3. Sistem pendukung keputusan ini dapat membantu pihak YPI. Asy-Syafi'iyah Internasional Medan dalam menentukan siswa yang layak mengikuti lomba LKS bidang desain grafis.

4. Sistem pemilihan Siswa untuk Berpartisipasi dalam Lomba Kompetensi Siswa Bidang Desain Grafis menggunakan Metode Elimination Et Choix Traduisant la Realite (ELECTRE) yang didapat dari hasil perhitungan nilai akhir adalah sesuai dengan perhitungan manual..

\section{REFERENSI}

[1] A.S Rosa \& Shalahuddin M. 2016. Rekayasa Perangkat Lunak Terstruktur dan Berorientasi Objek. Bandung : Informatika

[2] Kusumadewi, Sri, Hartati, Harkojo, Wardoyo. 2006. Fuzzy Multi Attribute Decision Making (FUZZY $M A D M)$. Yogyakarta : Graha Ilmu.

[3] Danton Sihombing, MFA 2001. TIPOGRAFI dalam desain grafis. Jakarta : Gramedia Pustaka Utama

[4] Sulindawati dan Muhammad Fathoni, 2010. Jurnal SAINTIKOM Vol. 9, No. 2 Agustus 2010

[5] Kusrini, M.Kom. 2007. Konsep dan Aplikasi Sistem Pendukung Keputusan. Yogyakarta : Andi

[6] A.M. Hirin. 2011. Belajar Tuntas VB.NET 2010 (Dari Dasar Sampai Mahir. Jakarta. PT. Prestasi Pusta Karaya

[7] Djoko Pramono. 2011. Manajemen Database Relasional dengan Access 2010. Jakarta : PT. Elex 